\title{
THE INFLUENCE OF PRESSURE ON THE LIQUID HOLD-UP IN A COCURRENT GAS-LIQUID TRICKLE-BED REACTOR OPERATING AT LOW GAS VELOCITIES
}

\author{
W. J. A. WAMMES, S. J. MECHIELSEN and K. R. WESTERTERP \\ Department of Chemical Engineering, Chemical Reaction Engineering Laboratories, University of Twente, \\ PO Box 217, 7500 AE Enschede, Netherlands
}

(Received 10 January 1990; accepted 3 April 1990)

\begin{abstract}
The influence of reactor pressure up to 6.0 MPa on the dynamic liquid hold-up in the trickle-flow regime with superficial gas velocities up to $5.2 \mathrm{~cm} / \mathrm{s}$ has been investigated for watcr, ethanol and aqucous $40 \%$ ethyleneglycol, with nitrogen as the gas phase. Without gas flow, i.e. single-liquid trickle-flow operation, the reactor pressure has no influence on the dynamic liquid hold-up, which can be well correlated by means of the Reynolds and Galileo numbers. For $R e_{1}<11$ the hold-up is proportional to $\operatorname{Re}_{1}^{0.36}$ and for $R e_{1}>15$ to $R e_{l}^{0.55}$. This is probably due to a transition between laminar and turbulent film flow. According to the literature the dynamic liquid hold-up is not affected by low gas velocities under atmospheric conditions. The experiments show that in the case of two-phase flow operation at elevated pressures the hold-up decreases at relatively low gas velocities and even more so at higher pressures. This effect has been explained quantitatively by means of the ratio between the pressure gradient and the gravitational force. In addition, the change in the dependence of $\beta_{\mathrm{d} y \mathrm{n}}$ on $R e_{I}$ has not been observed anymore: at low Reynolds numbers the hold-up is already proportional to $R e_{i}^{0.55}$.
\end{abstract}

\section{INTRODUCTION}

In a cocurrent gas-liquid trickle-bed reactor a gas and liquid phase flow downward over a fixed bed of catalyst particles. This type of three-phase catalytic reactor is widely used in the chemical and petrochemical industries, mostly at elevated pressures, e.g. the hydrodesulfurization of oil products.

The total hold-up of the liquid phase in the packed bed consists of two portions, the internal liquid holdup held inside the pores of the catalyst due to the capillary forces and the external hold-up partially occupying the void volume of the packed bed. For the reactor design the external liquid hold-up is a basic parameter because it is related to other important hydrodynamic parameters: the pressure gradient, the external wetting of the catalyst and the mean residence time of the liquid phase. To determine the external liquid hold-up two different methods are generally applied. The first method involves performing liquid phase residence time distribution (RTD) experiments in a packed bed of non-porous particles. The external liquid hold-up can be calculated from the first moment-the mean residence time - of the RTD curve. The disadvantage of this method is that the relatively long tail of the curve, due to the presence of more or less stagnant liquid zones around the contacting points of the particles, is difficult to mcasurc accuratcly. This can lead to large errors in the calculation of the first moment. The second method of determining the total external liquid hold-up is by means of performing weighing

†Author to whom correspondence should be addressed. experiments. After the reactor has reached its desired operating point the gas and liquid inlet are closed simultaneously. The amount of liquid trickling out of the column is commonly called the dynamic hold-up and the amount remaining in the packed bed is the static or residual hold-up. Consequently, the total external liquid hold-up is equal to the sum of the dynamic and the static hold-up.

The static hold-up, situated around the contacting points of the particles, results from the balance between the capillary and gravitational forces, and is independent of the gas flow, liquid flow and liquid viscosity [see Shulman et al. (1955)]. van Swaaij (1967) and Charpentier et al. (1968) proposed a relationship between the static hold-up and the dimensionless Eötvös number, $E \ddot{o}=\rho_{l} g d_{p}^{2} / \sigma_{i}$. At high Ë̈ the static hold-up is inversely proportional to $E \ddot{o}$ whereas at low Eä the static hold-up reaches a maximum value.

The correlation gives in the case of perfectly wettable solids fairly good estimates of the static holdup for different particle geometries and sizes. Sáez and Carbonell (1985) used the hydraulic diameter, instead of the nominal particle diameter, as the characteristic length in $E \ddot{o}$ to include the influence of the particle geometry on the static hold-up. However, no improvement could be obtained from correlating the data with this new representation.

In the literature (see Table 1) several studies have been presented on the dynamic liquid hold-up without gas flow or at low gas velocities. All these studies have in common that they were performed under atmospheric conditions. A comparison of the dynamic liquid hold-up equations shows several different relations for the influence of the superficial liquid velocity 
Table 1. Correlations presented in the literature for dynamic liquid hold-up for single-liquid flow operation or two-phase flow at low gas velocities under atmospheric conditions

\begin{tabular}{|c|c|}
\hline $\begin{array}{l}\text { Satterfield and Way (1972) } \\
0.02<R e_{l}<7.1 \\
0<v_{g}<2.3 \mathrm{~cm} / \mathrm{s}\end{array}$ & $\beta_{\mathrm{dyn}}=A v_{l}^{1 / 3} \eta_{l}^{1 / 4}+B$ \\
\hline $\begin{array}{l}\text { Goto and Smith }(1975) \\
0.3<R e_{i}<16 \\
0<v_{g}<0.8 \mathrm{~cm} / \mathrm{s}\end{array}$ & $\beta_{\mathrm{d} y \mathbf{n}}=A v_{l}^{1 / 3} \eta_{i}^{1 / 4}$ \\
\hline $\begin{array}{l}\text { Specchia and Baldi (1977) } \\
0.3<R e_{i}<3000\end{array}$ & $\beta_{\mathrm{dyn}}=3.86 R e_{l}^{0.545} \mathrm{Ga}_{l}^{-0.42}\left(\frac{a_{\mathrm{v}} d_{p}}{c}\right)^{0.65}$ \\
\hline $\begin{array}{l}\text { Kohler and Richarz (1984) } \\
0.1<R e_{i}<5\end{array}$ & $\beta_{\mathrm{dyn}}=3.42 R e_{l}^{0.545} G a_{l}^{-0.42}\left(\frac{a_{v} d_{p}}{\varepsilon}\right)^{n .65}$ \\
\hline $\begin{array}{l}\text { Buchanan }(1967) \\
0.03<R e_{i}<630\end{array}$ & $\beta_{\mathrm{dyn}}=A\left(\frac{R e_{l}}{G a_{l}}\right)^{1 / 3}+B\left(\frac{R e_{l}^{2}}{G a_{l}}\right)^{1 / 2}$ \\
\hline $\begin{array}{l}\text { Saez and Carbonell (1985) } \\
0.2<R e_{l}^{*}<2000\end{array}$ & $\beta_{\mathrm{dyn}}=\left(A \frac{\operatorname{Re} e_{l}^{*}}{G a_{l}^{*}}+B \frac{\operatorname{Re} e_{l}^{* 2}}{G a_{l}^{*}}\right)^{0.41}$ \\
\hline
\end{tabular}

$v_{l}$ or the liquid phase Reynolds number $R e_{l}$. In general $\beta_{\mathrm{d} y n}$ is correlated with $v_{l}^{p}$, where the value of $p$ depends on the liquid texture-laminar film, turbulent film, rivulets, drops-at the particle surface [see Charpentier et al (1968)]. Brauer (1971) reported the existence of a critical liquid throughput at which the hydrodynamic behaviour changes from laminar film flow, with $p=1 / 3$, to turbulent film flow, with $p$ $=0.5-0.6$. For relatively low Reynolds numbers Satterfield and Way (1972) and Goto and Smith (1975) found a value of $p=1 / 3$ corresponding to the laminar film flow texture. This is in contrast to the work of Kohler and Richarz (1984) who related $\beta_{\text {ayn }}$ to $v_{l}^{0.53}$ already for low values of $R e_{l}$. Based on a theoretical analysis Buchanan (1967) and Sáez and Carbonell (1985) correlated the dynamic hold-up in terms of two dimensionless expressions: $\left(R e_{l} / G a_{l}\right)^{1 / 3}$ and $R_{e} / G_{a l}{ }^{1 / 2}$. The first expression corresponds to a hydrodynamic flow pattern with energy losses mainly due to viscous friction of the liquid at the packing surface. The second expression has been derived on the basis of energy losses caused by turbulences due to regular changes in the velocity pattern at the packing. In this type of hold-up correlations both conditions are combined into one equation. None. of the aforementioned studics noticed any significant effect of the gas-liquid surface tension on the dynamic liquid holdup.

In the case of two-phase flow operation with relatively low gas flows no influence on $\beta_{\mathrm{dyn}}$ has been found for the gas fiow rate as can be concluded from the investigations of Satterfield and Way (1972) and Goto and Smith (1975). Similar observations have been reported by Charpentier and Favier (1975) and Morsi et al. (1978).

Recently Levec et al. (1986, 1988) found that the dynamic liquid hold-up exhibits multiple steady states even without gas flow. When the flow rate was adjusted by reducing a high throughput, the hold-up at equal loads was larger than by increasing the flow rate after the drain period. In the latter case the liquid flows in the form of rivulets which change into a film only at a relatively high throughput. However, in the decreasing mode the liquid film is more stable due to the contact angle hysteresis and breaks into rivulets only at a lower throughput. Based on several observations they concluded that the existence of multiplicity in hydrodynamic states is a consequence of the imperfect wetting of the packing.

The main objective of our study is to investigate the dynamic liquid hold-up as a function of the liquid velocity and the reactor pressure without gas flow or at low velocities of $1.9 \leqslant v_{g} \leqslant 5.2 \mathrm{~cm} / \mathrm{s}$. Also attention will be paid to possible hysteresis phenomena. Furthermore the static liquid hold-up at low E $\ddot{o}$ will be investigated. The experiments are performed with water, ethanol and aqueous $40 \%$ ethyleneglycol, with nitrogen as the gas phase in a trickle-bed installation with a maximum operating pressure of $6.0 \mathrm{MPa}$.

\section{EXPERIMENTAL SET-UP}

A detailed description of the experimental installation used in this study has been given by Wammes et al. (1990). Here we will only give a brief description of the set-up. A flow sheet of the installation is given in Fig. 1. The trickle-bed reactor (4) has an inner diameter of $51 \mathrm{~mm}$ and is packed with thoroughly cleaned glass spheres of $3 \pm 0.5 \mathrm{~mm}$ in diameter. The height of the packed bed is $2.62 \mathrm{~m}$ and it has an overall porosity of 0.39 . A spray device has been locuted above the top of the bed in order to minimize the entrance effects by distributing the liquid phase evenly. Provisions have been made to measure the pressure at the top, the temperature at the top and the bottom of the bed and the pressure 


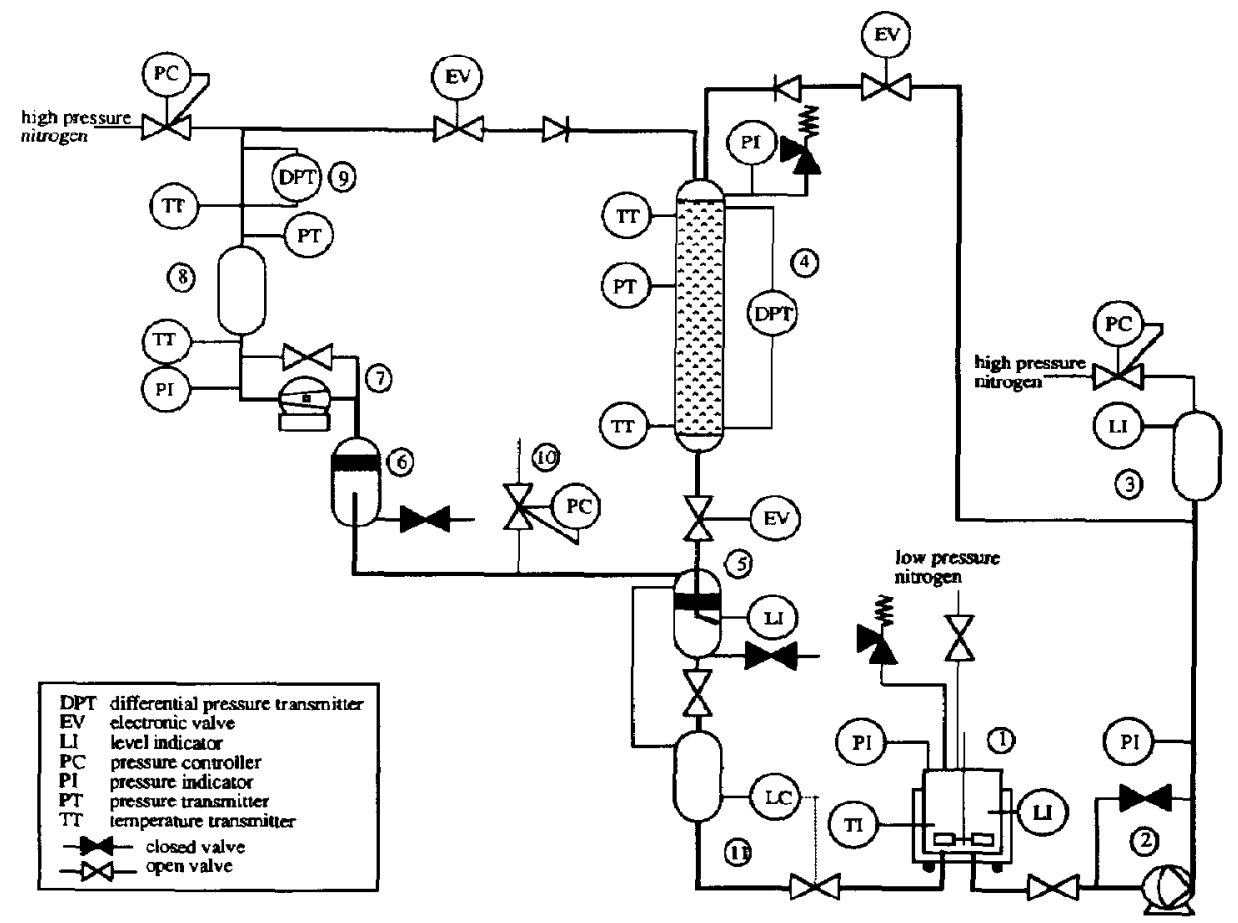

Fig. 1. Flow sheet of our experimental installation: $1=$ liquid storage vessel at $0.05 \mathrm{MPa}, 2=$ liquid pump, 3 = air-chamber, 4 - trickle-bed reactor, $5=$ gas -liquid separator, $6=$ demister, $7=$ gas booster, $8=$ gas buffers, 9 = orifices, $10=$ system back pressure, $11=$ level-controlled buffer vessel.

Table 2. Physical properties at $293 \mathrm{~K}$ of the liquids used in this study

\begin{tabular}{lccc}
\hline & \multicolumn{3}{c}{ Physical property } \\
\cline { 2 - 4 } & $\begin{array}{c}\rho_{l} \\
\left(\mathrm{~kg} / \mathrm{m}^{3}\right)\end{array}$ & $\left(\times 10^{3} \mathrm{~N} / \mathrm{m}^{2}\right)$ & $\left(\times 10^{\sigma^{3}} \mathrm{~N} / \mathbf{m}\right)$ \\
\hline Water & 1000 & 1.0 & 72 \\
$40 \%$ ethyleneglycol & 1050 & 2.9 & 60 \\
Ethanol & 790 & 1.2 & 22 \\
\hline
\end{tabular}

difference over the packed bed. A reactor section of $1 \mathrm{~m}$ length has been manufactured in transparent polycarbonate material, by which we are able to visualize the flow regime.

The installation has been designed for operating pressures up to $7.5 \mathrm{MPa}$ at a temperature of $293 \mathrm{~K}$. The maximum superficial liquid and gas velocitybased on the empty cross-section of the reactor-are, respectively, 1.6 and $35 \mathrm{~cm} / \mathrm{s}$. The gas throughput is measured by means of an orifice meter (9) and the liquid flux is determined from the pump (2) calibration curves. A programmable Analog Devices $\mu \mathrm{mac} 5000$ data acquisition and control unit connected to an Apple2C computer is used for the monitoring and the continuous control of the level in the buffer vessel (11), the electronical valves, the pump piston stroke length, the pressure, differential pressure and temperature transmitters, and the superficial gas and liquid velocity in the reactor. The pressure in the set-up is adjusted manually by means of a back pressure regulator (10). The physical properties of the gas-liquid systems used in this study are listed in Table 2.

\section{EXPERIMENTAL METHOD}

Before the experiments are started the packing is prewetted by means of operating the reactor in the bubble flow regime followed by draining.

During the experimental runs, the reactor operation is assumed to be stable when the reactor pressure, temperature and pressure drop and the liquid and gas throughput do not alter for at least $5 \mathrm{~min}$ after changing the operating variables. The dynamic liquid holdup is determined by the weighing method: the magnetic valves in the gas and liquid inlet pipes and the reactor outlet are closed simultaneously. The gas-liquid separator is emptied and then its bottom valve is closed. Next the reactor outlet valve is opened 
so that the liquid trickles out of the column into the separator. During the draining period, which takes place under the operating pressure, the pressure in the separator and at the top of the column are equalized by means of a bypass. After collecting the dynamic liquid hold-up entirely it is pressed out of the separator and weighed. The dynamic liquid hold-up is calculated by means of

$$
\beta_{\mathrm{dyn}}=\frac{W_{l}}{\rho_{l} \varepsilon V_{r}} .
$$

The minimum time of draining necessary to empty the column was $30 \mathrm{~min}$ for water and ethanol, and $1 \mathrm{~h}$ for the aqueous $40 \%$ solution of ethyleneglycol. Data are reproducible within a relative error of $5 \%$.

To investigate whether the $\beta_{\mathrm{dyn}}$ value depends on the way by which the operating point has been reached two procedures are used: the liquid flow rate is reduced to its desired value starting at its maximum throughput or the flow rate is increased from a relatively low set point. A similar procedure has been followed for the gas flow rate.

The residual liquid hold-up measurements are performed at atmospheric pressure in a trickle-bed reactor of $50 \mathrm{~mm}$ in diameter, a packed bed height of $0.6 \mathrm{~m}$ and an overall bed porosity of 0.39 . The reactor has been packed with the same packing material and the same packing procedure is used as for the highpressure trickle-bed reactor. The reactor is flooded with the liquid phase and after the minimum time of draining the complete reactor is weighed. From the difference from the weight of the reactor with a dry packing the residual hold-up can be calculated. Data are reproducible with a relative error of maximal $10 \%$.

\section{RESULTS AND DISCUSSION}

\section{Static liquid hold-up}

The experimentally determined values of $\beta_{\text {stat }}$ are plotted in Fig. 2 as a function of Ë̈ together with data of other authors and the diagram of van Swaaij (1967) and Charpentier et al. (1968). In our opinion the static or residual liquid hold-up is not affected by the reactor pressure. Our data confirm the proposal of van Swaaij and Charpentier that at low Eö the static holdup is limited to a value of $c \beta_{\text {stat }} \approx 0.05$, where $\varepsilon$ is the

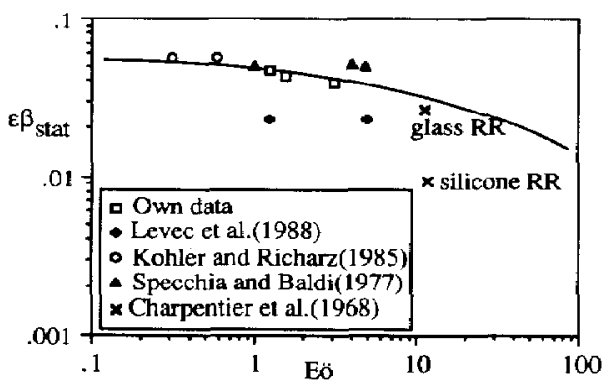

Fig. 2. Static liquid hold-up as a function of the Eötvos number. void fraction of the packed bed. Deviations from the correlation are caused by neglecting the wetting properties of the solid surface [see van Swaaij (1967) and Charpentier et al. (1968)]: in the case of a liquid-solid system with poor wetting properties the amount of static liquid is overestimated. Consequently, the static liquid hold-up experiments can be used to judge the wetting conditions in a liquid-solid system. The static hold-up value reported by Levec et al. (1986) is much lower compared to our value (see Fig. 2), although the same system was used: water and 3-mm glass spheres. Therefore it is likely that their glass surface had poor wetting properties, promoting rivulet flow and imperfect wetting of the packing except for high liquid loads.

The wetting properties of a material, which can be evaluated by means of the liquid-solid contact angle, are favoured by a low gas-liquid surface tension and a high free surface energy of the material, such as clean glass. Besides these factors, the roughness of the solid surface plays a role but its influence is difficult to predict a priori [see Hüttinger and Bauer (1982)].

In most cases the wetting property is an unknown parameter: moreover, it is sensitive to surface contaminations. We inspected our system by taking out a batch of glass spheres of the reactor atter the draining period. For the three liquids we used in this study, we observed that the glass surface was fully covered with a very thin liquid film, implying good wetting properties of our packing material. This does not necessarily mean that the packing is also completely actively wetted by the liquid flow at each liquid flow rate.

\section{Dynamic liquid hold-up without gas flow}

The results of the dynamic liquid hold-up experiments with water as a function of $R e_{i}$ have been plotted in Fig. 3. From a comparison between the hold-up values determined at 0.3 and $6.0 \mathrm{MPa}$ it can be concluded that without gas flow the reactor pressure has no influence on the hold-up. Moreover, the hydrodynamic state in the column shows no hysteresis: the way in which the operating point has been set has no influence on the dynamic liquid hold-up value. This has also been observed for the experiments with ethanol and aqueous $40 \%$ ethyleneglycol. From these

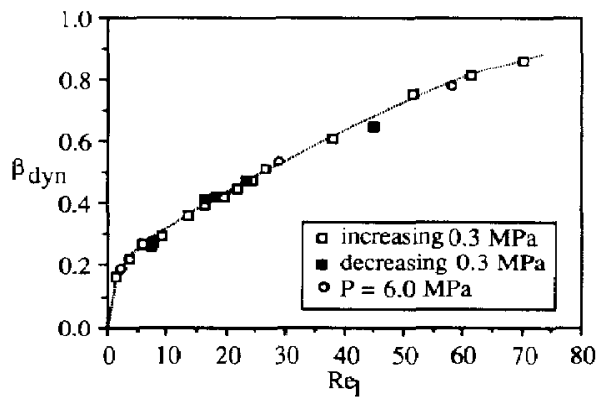

Fig. 3. Influence of reactor pressure and liquid flow rate adjustment on the dynamic liquid hold-up for single-liquid trickle-flow operation with water. 
findings we conclude that the liquid flow pattern at each liquid throughput does not depend on any previous operating conditions.

In Fig. $4 \beta_{\text {dyn }}$ has been plotted for all three different liquids as a function of $R e_{l}$. The dynamic liquid holdup measurcments with the aqueous $40 \%$ ethyleneglycol solution were limited to superficial liquid velocities no higher than $8 \times 10^{-3} \mathrm{~m} / \mathrm{s}$. Beyond this condition flooding started in the free space above the top of the bed. In Fig. 4 two different ranges can be distinguished:

$$
\begin{aligned}
& R e_{i}<11: \beta_{\mathrm{dyn}} \sim R e^{0.36} \\
& R e_{i}>15: \beta_{\mathrm{dyn}} \sim R e_{l}^{0.55}
\end{aligned}
$$

and in the relatively small intermediate range the exponent changes gradually from 0.36 to 0.55 . A similar observation has been reported by Brauer (1971) for the countercurrent operation below the loading point. Our findings for $R e_{l}<11$ are in accordance with Satterfield and Way (1972) and Goto and Smith (1975), but contradict those of Kohler and Richarz (1985), who reported an exponent of 0.53 for low $R e_{l}$ (see Table 1). For $R e_{l}>15$ the relation between $\beta_{\mathrm{d} y \mathbf{n}}$ and $R e_{l}$ is similar to the findings of Specchia and Baldi (1977) up to $R e_{1}=3000$.

It has been difficult to observe the type of liquid flow pattern through the transparent column wall because only the wall area is seen. In this region the structure of the packed bed differs from the core region: moreover, the flow pattern is influenced by the regular contact with the column wall, which has been manufactured in polycarbonate with poor wetting properties. The following considerations lead us to the conclusion that at each flow rate the liquid is flowing mainly as a liquid film over the packing. As can be concluded from the static hold-up experiments the wetting properties of the glass spheres are optimal, which promotes the film flow pattern for the three different liquids. In the case when the liquid flows predominantly in the form of rivulets a decrease in the gas-liquid surface tension would reduce the liquid-solid contact angle and therefore improve the degree of wetting and liquid hold-up [see Shi and Mersmann (1984) and Levec et al. (1986)]. However,

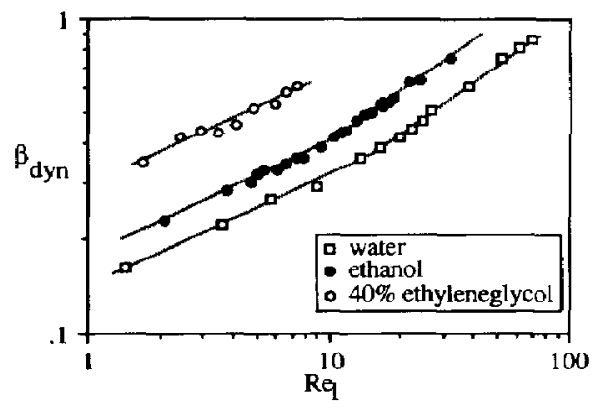

Fig. 4. Dependence of dynamic liquid hold-up on the Reynolds number in single-liquid trickle-flow operation at atmospheric pressure. our dynamic liquid hold-up experiments did not show any noticeable effect of $\sigma_{t}$ on $\beta_{\mathrm{dyn}}$ as will be seen later.

The transition in Fig. 4 is determined by $R e_{t}$ and is independent of the gas liquid surface tension. Therefore we presume that at the transition the flow pattern changes from a regime dominated by laminar films to a flow regime where the films are turbulent.

A description of the liquid hold-up and its relation to the hydrodynamics is extremely difficult due to, for example, the complex structure of the packing, the uncertainty of the wetted area and the complexity of the flow pattern. Therefore we restricted ourselves to a function of dimensionless numbers. For the single liquid trickle-flow experiments the hold-up $\beta_{\mathrm{dym}}$ can be correlated with $R e_{l}$, the Galilen number $G a_{l}$ and a variable $F$, taking into account the influence of the packing properties. $G a_{1}$ represents the ratio of $R e_{r}^{2}$ and the liquid Froude number. For both $R e_{l}$ ranges (see Fig. 4) we correlated the data by means of a power law relation and obtained

$$
\begin{aligned}
& \beta_{\mathrm{d} y \mathrm{n}}=16.3\left(\frac{p_{l} v_{t} d_{p}}{\eta_{l}}\right)^{c_{1}}\left(\frac{d_{p}^{3} \rho_{l}^{2} g}{\eta_{l}^{2}}\right)^{c_{2}} \\
& R e_{1}<11: \quad c_{1}=0.36, \quad c_{2}=-0.39 \\
& R e_{1}>15: \quad c_{1}=0.55, \quad c_{2}=-0.42 .
\end{aligned}
$$

The three different liquids are equally well correlated with eq. (2) and therefore the assumption that $\sigma_{1}$ has no influence is justified. It should be mentioned that for foaming systems the gas-liquid surface tension effects on the liquid hold-up cannot be neglected [see, for example, Charpentier and Favier (1975)].

Our findings about the dependence of $\beta_{\mathrm{cyn}}$ on $R e_{l}$ and $G a_{l}$ in the range $R e_{l}>15$ are in agreement with the work of Specchia and Baldi (1977) (see Table 1). Because the packing properties were not varied in our study, the constant in eq. (2) depends on the type of packed bed. Specchia and Baldi (1977) accounted for the effect of the packing properties by $\left(a_{v} d_{p} / \varepsilon\right)^{0.65}$, which has been based on many data for porous and non-porous packings of different geometry and size with a nominal diameter in the range of $0.5<d_{p}<50 \mathrm{~mm}$. When we substitute the value $\left(a_{v} d_{p} / \varepsilon\right)^{0.65}$ of our packed bed into the constant, a factor 3.8 results, compared to 3.86 found by Specchia and Baldi (1977) and 3.46 by Kohler and Richarz (1985). Rao and Drinkenburg (1985) also found for a spherical packing a good agreement with the correlation of Specchia and Baldi (1977), but not for Raschig rings. A comparison between the experimental data and the prediction by means of eq. (2) is given in Fig. 5.

Pressure influence on the dynamic liquid hold-up at low gas velocities

In the case of a gas-liquid flow at relatively low gas velocities the trickle-bed reactor operates in the trickle-flow regime. The gas phase is continuous and practically does not influence the liquid hold-up [see, for example, Shah (1979) and Ramachandran and 


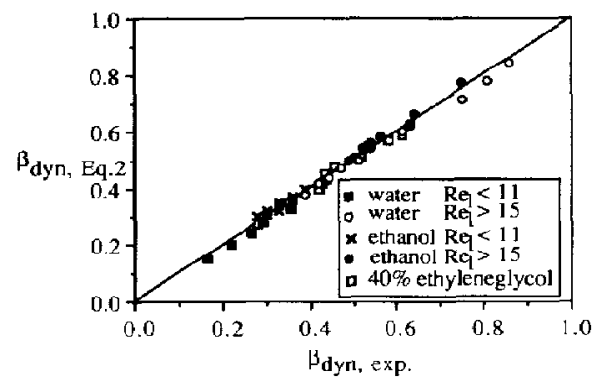

Fig. 5. Comparison between the experimental dynamic liquid hold-up values and the correlation given by eq. (2).

Chaudari (1983)]. Therefore this flow behaviour is often described as the "low interaction regime": however, it should be noted that these conclusions are based on experiments at atmospheric pressure.

In Figs 6 and 7 our results are given for the dynamic liquid hold-up experiments with water-nitrogen and aqueous $40 \%$ ethyleneglycol-nitrogen at different reactor pressures. Under all conditions the reactor operated in the trickle-flow regime: no pulses or gas bubbles could be seen through the transparent part of the column. Besides, the method of gas flow rate adjustment, which has been varied for several experimental runs, did not influence the dynamic liquid hold-up and pressure drop. The hold-up values measured under no gas flow conditions, which are independent of the reactor pressure as has been concluded in the foregoing paragraph, have also been plotted in Figs 6 and 7. Figure 6 shows that a pressure increase at a low liquid flow rate and gas velocity has no significant effect on the dynamic liquid hold-up. At higher liquid throughputs and with the reactor operating at $0.5 \mathrm{MPa}$, an increase in the superficial gas velocity reduces the liquid hold-up. This decrease becomes more substantial at higher reactor pressures. Similar trends are observed for the aqueous $40 \%$ ethyleneglycol-nitrogen system in Fig. 7. For this system, even at low $R e_{l}$ values the influence of the superficial gas velocity and the reactor pressure on the dynamic liquid lould-up is noticeable.

Hence it appears that the application of hold-up correlations, derived from the single-liquid trickleflow experiments, to estimate the liquid hold-up in high-pressure trickle-bed reactors operating at low superficial gas velocities can lead to serious overestimations. We recommend abstaining from the use of the term "low interaction regime" for the trickleHow regime: there is definitely a high influence of the gas flow on the hydrodynamics at higher pressures in the trickle-flow regime, even at relatively low gas velocities.

The decrease in the dynamic liquid hold-up in the two-phase operation at elevated reactur pressures can be explained by accounting for the drag force at the gas-liquid interface. This force depends on the gas velocity as well as the gas density and is, together with the gravitational force, the driving force for the liquid

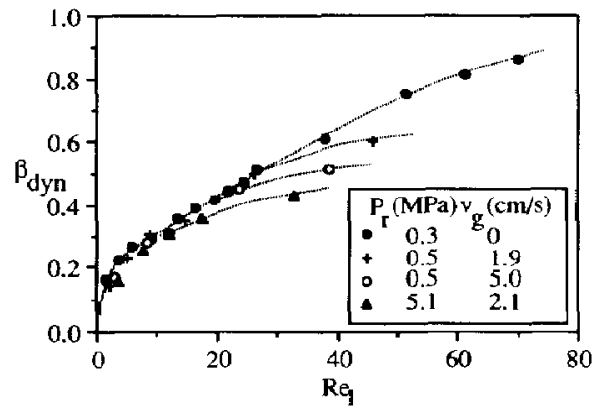

Fig. 6. Dynamic liquid hold-up at low gas velocities and elevated pressures in comparison with single-liquid trickleflow operation for water-nitrogen system.

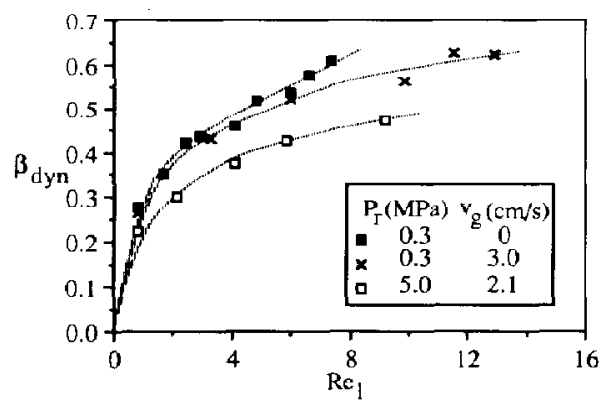

Fig. 7. Dynamic liquid hold-up at low gas velocities and elevated pressures in comparison with single-liquid trickleflow operation for aquenus $40 \%$ ethyleneglycol-nitrogen system.

flow. At atmospheric pressure and low gas velocities the drag force is negligible in comparison with the gravitational force. Under these conditions the dynamic liquid hold-up can be calculated from correlations based on single-liquid trickle-flow experiments [see, for example, Satterfield and Way (1972)] in Table 1. However, at elevated pressures the drag force can have a considerable influence at low gas velocities as is demonstrated in Figs 8 and 9. Here the ratio between the pressure gradient and the gravitational force has been plotted as a function of $R e_{l}$ for the same operating conditions as in Figs 6 and 7. From a comparison of Figs 6 and 8 and Figs 7 and 9 we see that for very low values of $\Delta P /\left(\rho_{1} g L\right)$ the dynamic liquid hold-up is nearly equal to that under operating conditions without gas flow. But the more this ratio increases the greater $\beta_{d y n}$ deviates from the hold-up without gas flow. It is obvious that at a reactor pressure of $5.0 \mathrm{MPa}$ the pressure gradient can have large values in relation to $\rho_{l} g$, although the superficial gas velocity is relatively low. For the ethanol-nitrogen system, having an intermediate value for the liquid viscosity, the abovementioned conclusions also hold.

In processing the effect of both the superficial gas velocity and the reactor pressure on the dynamic 


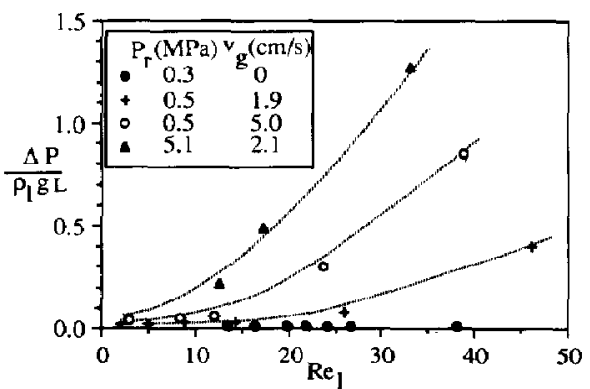

Fig. 8. Value of $\Delta P /\left(\rho_{1} g L\right)$ as a function of $R e_{l}$ for waternitrogen system at different reactor pressures and gas velocities.

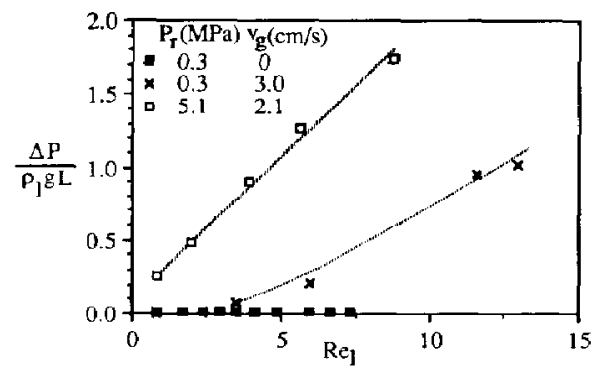

Fig. 9. Value of $\Delta P /\left(\rho_{1} g L\right)$ as a function of $R e_{l}$ for aqueous $40 \%$ ethyleneglycol-nitrogen system at different reactor pressures and gas velocities.

liquid hold-up quantitatively, good results have been obtained by using the modified Galileo number

$$
G a_{l}=G a\left(1+\frac{\Delta P}{\rho_{l} g I}\right)=\left(\frac{d_{p}^{3} \rho_{l}^{2} g}{\eta_{l}^{2}}\right)\left(1+\frac{\Delta P}{\rho_{l} g L}\right)
$$

in eq. (2). This modification is similar to the proposal of Specchia and Baldi (1977).

The constant and exponents in eq. (2), but now with $G a$, have been recalculated from the data set consisting of all our gas-liquid flow measurements. The numerical values have been found the same as those for the single-liquid trickle-flow experiments in the turbulent range:

$$
\begin{aligned}
\beta_{\mathrm{dyn}}= & 3.8\left(\frac{\rho_{\mathrm{l}} v_{l} d_{p}}{\eta_{l}}\right)^{0.55}\left[\frac{d_{p}^{3} \rho_{l}^{2} g}{\eta_{l}^{2}}(1\right. \\
& \left.\left.+\frac{\Delta P}{\rho_{l} g L}\right)\right]^{-0.42}\left(\frac{a_{v} d_{p}}{\varepsilon}\right)^{0.65} .
\end{aligned}
$$

A comparison between the predicted and measured values for the three gas-liquid systems is given in Fig. 10. So, to account for the effect of the reactor pressure and the superficial gas velocity on the dynamic liquid hold-up, the relative contribution of the pressure gradient in relation to the gravitational force must be incorporated into the dynamic liquid hold-up correlation derived from the single-liquid trickle-flow experiments. However, a transition to a laminar flow regime has not been observed anymore for the twophase flow experiments (see Fig. 11): already at low Reynolds numbers the liquid flow pattern is dominated by turbulences. The dynamic liquid hold-up correlations of Satterfield and Way (1972), Charpentier and Favier (1975) and Brauer (1971) show that relatively low gas velocities do not change the value of the exponent of $v_{l}$ for co- or countercurrent operation under atmospheric conditions; the liquid flow pattern is not effected by the low drag forces at the gas-liquid interface. In our experiments at elevated pressures, the shear stresses at the gas-liquid interface are higher, following from the pressure drop data. This interaction may cause turbulences in the liquid film, despite the low $R e_{\text {: }}$ value. The shear stress can be calculated from the pressure gradient and the specific gas-liquid interfacial area. Unfortunately we have not been able to determine the lower limit of shear stress where the influence on the liquid flow pattern becomes negligible: we could not operate our installation stabily at pressures below $0.3 \mathrm{MPa}$ and velocities $v_{8}<1.9 \mathrm{~cm} / \mathrm{s}$ which were required to study this phenomenon.

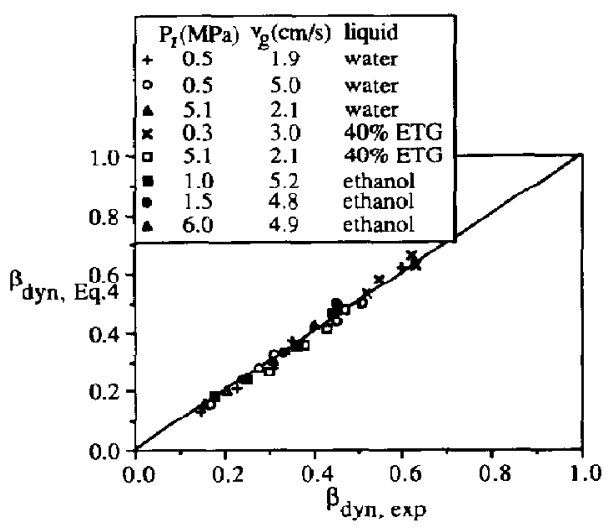

Fig. 10. Comparison between the experimental dynamic liquid hold-up values and the correlation given by eq. (4).

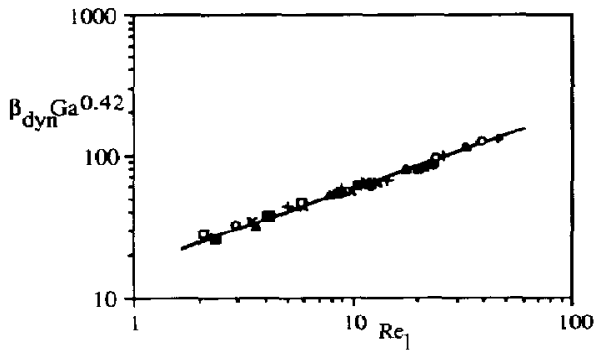

Fig. 11. Dependence of dynamic liquid hold-up on the Reynolds number for two-phase flow operation at elevated pressures. The symbols are listed in Fig. 10. 


\section{CONCLUSIONS}

In the literature not much information is available on the total external liquid hold-up in a cocurrent gas-liquid trickle-bed reactor operating at elevated pressures. In this study dynamic liquid hold-up experiments have been discussed in the trickle-flow regime with nitrogen and water, ethanol and aqueous $40 \%$ ethyleneglycol at low superficial gas velocities of $1.9 \leqslant v_{g} \leqslant 5.2 \mathrm{~cm} / \mathrm{s}$, and without gas flow for reactor pressures up to $6.0 \mathrm{MPa}$. The static liquid hold-up measurements have been performed in a separate column under atmospheric conditions because we considered this to be pressure-independent.

With respect to the static hold-up our experiments have been restricted to low Eö. The results are very well described by the diagram of van Swaaij (1967) and Charpentier et al. (1968).

In the single-liquid trickle-flow operation the dynamic liquid hold-up is pressure-independent and shows no hysteresis. A change in the liquid flow pattern, probably from laminar to turbulent film flow, is observed at $R e_{i}$ in the range $11<R e_{2}<15$. The experimental data are well correlated by using the dimensionless numbers $R e_{l}$ and $G a_{l}$ [see eq. (2)]. The same correlations are also applicable to two-phase flow at atmospheric pressure when $\Delta P /\left(\rho_{l} g L\right) \ll 1$.

In the case of two-phase flow at elevated pressures the transition in the liquid flow pattern has not been observed anymore, probably due to the relatively higher shear stresses at the gas-liquid interface. Already for $R e_{l}>1$ the hold-up is proportional to $R e_{\ell}^{0.55}$. In contrast to the operation at atmospheric pressure a small increase in the superficial gas velocity reduces the dynamic liquid hold-up considerably compared to the single-liquid trickle-flow operation. The decrease is more pronounced at higher $R e_{i}$ values and reactor pressures. This effect has been explained by the high values of the pressure drop at elevated pressures, even at low gas velocities. The influence of the superficial gas velocity and reactor pressure on the hold-up can be integrated into the correlation derived from the single-liquid trickle-flow experiments by using the Galileo number [see eq. (3)].

In our investigations nitrogen has been used as the gas phase. We expect that in the case of operation with gases having a much lower molecular weight, e.g. $H_{2}$, the ratio $\Delta P /\left(\rho_{l} g L\right)$ will generally be much smaller. Therefore the error in the estimate of the dynamic liquid hold-up at low gas velocities and elevated pressures from the single-liquid trickle-flow operation will probably be less pronounced.

Acknowledgements - The investigations were financially supported by DSM Research B. V. (Geleen. Netherlands) and the Netherlands Foundation for Chemical Research (STW). We further want to thank A. H. Pleiter and assistants, and G. H. Banis for their technical support.

\section{NOTATION}

A constant in Table 1

$a_{v}$ specific external surface area of the packing, $\mathrm{m}^{2} / \mathrm{m}^{3}$
$B \quad$ constant in Table 1

$d_{p} \quad$ nominal particle diameter, $m$

$d_{e} \quad$ equivalent packing diameter, $\mathrm{m}$

Eö Eötvos number $\left(\rho_{t} g d_{p}^{2} / \sigma_{i}\right)$

$G a_{l} \quad$ Galileo number $\left(d_{p}^{3} \rho_{l}^{2} g / \eta_{l}^{2}\right)$

$G a_{l}^{*}$ modified Galileo number $\left\{\rho_{l}^{2} g d_{e}^{3} \varepsilon^{3} /[(1\right.$ $\left.-\varepsilon)^{3} \eta_{i}^{2}\right]$ ?

$G a_{i}$ modified Galileo number $\left\{G a_{l}[1+(\Delta P /\right.$

\section{$\left.\left.L) /\left(\rho_{1} g\right)\right]\right\}$}

$P$, reactor pressure, $\mathrm{MPa}$

$\Delta P / L$ reactor pressure gradient, $N / \mathrm{m}^{3}$

$R e_{l} \quad$ Reynolds number $\left(\rho_{l} v_{l} d_{p} / \eta_{l}\right)$

$\operatorname{Re}_{i}^{*} \quad$ Reynolds number $\left\{\rho_{l} v_{l} d_{e} \varepsilon /\left[(1-\varepsilon) \eta_{l}\right]\right\}$

$V_{r}$ volume of the packed-bed reactor, $\mathrm{m}^{3}$

$v_{g} \quad$ superficial gas velocity based on the empty reactor cross-section, $\mathrm{m} / \mathrm{s}$

$v_{l} \quad$ superficial liquid velocity based on the empty reactor cross-section, $\mathrm{m} / \mathrm{s}$

$W_{l} \quad$ weight of the liquid, $\mathrm{kg}$

\section{Greek letters}

$\beta_{\text {dyn }} \quad$ dynamic liquid hold-up, liquid volume in void volume

$\beta_{\text {stat }} \quad$ static liquid hold-up, liquid volume in void volume

$\varepsilon \quad$ overall porosity of the packed bed

$\eta_{l} \quad$ dynamic liquid viscosity, $\mathrm{N} s / \mathrm{m}^{2}$

$\rho_{1} \quad$ liquid density, $\mathrm{kg} / \mathrm{m}^{3}$

$\sigma_{l} \quad$ gas-liquid surface tension, $N / \mathrm{m}^{2}$

\section{REFERENCES}

Brauer, H., 1971, Grundlagen der Einphasen- und Mehrphasenströmungen p. 773. Sauerländer, trankfurt am Main.

Buchanan, J. E., 1967, Hold-up in irrigated ring-packed towers below the loading point. Ind. Engng Chem. Fundam. 6, 401-407.

Charpentier, J. C., Prost, C., van Swaaij, W. P. M. and LeGoff, P., 1968, Etude de la rétention de liquide dans une colonne à garnissage arrosé $\dot{a}$ co-courant et à contrecourant de gaz-liquide. Chim. Ind. Génie Chim. 99, 803-826.

Charpentier, I. C. and Favier, M., 1975, Some liquid hold-up experimental data in trickle-bed reactors for foaming and non-foaming hydrocarbons. A.I.Ch.E. J. 21, 1213-1218.

Goto. S. and Smith. J. M., 1975, Trickle-bed reactor performance. A.I.Ch.E. J. 21, 706-712.

Hüttinger, K. J. and Bauer, F., 1982, Benetzung und Stofaustausch in Filmkolonnen. Chemie-Ingr-Tech. 54, 449-460.

Kohler, M. and Richarz, W., 1984, Untersuchungen des Flüssigkeitsholdup in Rieselbettreaktoren. Chemie-IngrTech 56, 1-19.

Levec, J., Saez, A. E. and Carbonetl, R. G., 1986, The hydrodynamics of trickling flow in packed beds. A.J.Ch.E. J. 32 , $369-380$

Levec, J., Grosser, K. and Carbonell, R. G., 1988, The hysteretic behaviour of pressure crop and liquid hold-up in trickle-beds. A.I.Ch.E. J. 34, 1027-1030.

Morsi, B. I., Midoux, N. and Charpentier, J. C., 1978, Flow pattern and some hold-up experimental data in trickle-bed reactor for foaming and non-foaming viscous organic liquids. A.I.Ch.E. J. 24, 357-360.

Ramachandran, P. A. and Chaudari, R. V., 1983, Three Phase Catalytic Reactors, pp. 200-239. Gordon \& Breach, New York.

Rao, V. G. and Drinkenburg, A. A. H., 1985, A model for pressure drop in two-phase gas-liquid downflow through packed columns. A.I.Ch.E. J. 31, 1010-1018. 
Sáez, A. E. and Carbonell, R. G., 1985, Hydrodynamic parameters for gas-liquid cocurrent flow in packed beds. A.I.Ch.E. J. 31, 52-62.

Satterfield, C. N. and Way, P. F., 1972, The role of the liquid phase in the performance of a trickle-bed reactor. A.I.Ch.E. J. 18, 305-311.

Shah, Y. T., 1979, Gas-Liquid-Solid Reactor Design, pp. 180-207. MeGraw-Hill, New York.

Shi, M. G. and Mersmann, A., 1984, Effektive Austauschfläche in Füllkörperkolonnen. Chemie-Ingr-Tech. 56, 404-405.

Shulman, H. L., Ullrich, C. F and Wells, N., 1955, Per- formance of packed columns. A.I.Ch.E. J. 1, 248-264.

Specchia, V. and Baldi, G., 1977, Pressure drop and liquid hold-up for two-phase cocurrent flow in packed beds. Chem. Engng Sci. 32, 515-523.

van Swaaij, W. P. M., 1967, Residence time distributions in Raschig ring columns at trickJe flow. PhD thesis, University of Eindhoven.

Wammes, W. J. A., Mechielsen, S. J. and Westerterp, K. R., 1990, The transition between trickle flow and pulse flow in a cocurrent gas-liquid trickle-bed reactor at elevated pressures. Chem. Engng Sci. 45, 3149-3158. 